\title{
Improved Ruthenium Catalysts for Z-Selective Olefin Metathesis
}

\author{
Benjamin K. Keitz ${ }^{\ddagger}$, Koji Endo $\ddagger$, Paresma R. Patel, Myles B. Herbert, and Robert H. Grubbs ${ }^{\star}$ \\ Arnold and Mabel Beckman Laboratories of Chemical Synthesis, Division of Chemistry and \\ Chemical Engineering, California Institute of Technology, Pasadena, California, 91125
}

\begin{abstract}
Several new C-H activated ruthenium catalysts for Z-selective olefin metathesis have been synthesized. Both the carboxylate ligand and the aryl group of the $\mathrm{N}$-heterocyclic carbene have been altered and the resulting catalysts were evaluated using a range of metathesis reactions. Substitution of bidentate with monodentate X-type ligands led to a severe attenuation of metathesis activity and selectivity, while minor differences were observed between bidentate ligands within the same family (e.g. carboxylates). The use of nitrato-type ligands, in place of carboxylates, afforded a significant improvement in metathesis activity and selectivity. With these catalysts, turnover numbers approaching 1000 were possible for a variety of cross-metathesis reactions, including the synthesis of industrially-relevant products.
\end{abstract}

\section{INTRODUCTION}

Olefin metathesis is a powerful tool for the construction of new carbon-carbon bonds. ${ }^{1}$ The development of robust metathesis catalysts, ${ }^{2}$ which carry out this transformation, has facilitated the adoption of this methodology by a variety of fields including polymer chemistry, ${ }^{3}$ organic synthesis, ${ }^{4}$ biochemistry, ${ }^{5}$ and green chemistry. ${ }^{6}$ However, the synthesis of cis- or Z-olefins via olefin metathesis has persisted as a significant challenge. The attempts to address this problem can generally be divided into two areas, catalyst-control and substrate-control, with examples of the latter recently achieving notable successes. ${ }^{7}$ Selectivity via catalyst design, on the other hand, is much more challenging since the majority of catalysts prefer the thermodynamically favored $E$-olefin. It was not until the pioneering work of Schrock and Hoveyda that a catalyst-controlled system for the synthesis of Z-olefins via metathesis was finally realized. ${ }^{8}$ As a complement to their work, we sought to develop a functional group tolerant, ruthenium-based catalyst with similar levels of activity and selectivity.

Recently, we reported on the synthesis and activity of a ruthenium metathesis catalyst containing a Ru-C bond formed via carboxylate-induced intramolecular C-H activation (2). ${ }^{9}$ Structurally similar complexes have previously been isolated as metathesis decomposition products, but none were metathesis active. ${ }^{10}$ Thus, we were surprised to discover that $\mathbf{2}$ was not only metathesis active, but also showed unprecedented selectively for Z-olefins in a variety of cross-metathesis reactions.

Due to the dynamic nature of ruthenacyclobutanes, ${ }^{11}$ particularly when compared to molybdacycles and tungstacycles, the origin of the Z-selectivity in $\mathbf{2}$ has remained unclear.

*Corresponding Author: rhg@ caltech.edu.

¥Author Contributions

These authors contributed equally to this manuscript.

Supporting Information. Experimental and synthetic details as well as NMR spectra. This material is available free of charge via the Internet at http://pubs.acs.org. 
Nonetheless, structure-function relationships derived from systematic changes of $\mathbf{2}$ have demonstrated that the adamantyl group is critical for achieving high levels of $Z$-selectivity. ${ }^{9 a}$ Unfortunately, our attempts to make more drastic alterations have mostly led to decomposition during the $\mathrm{C}-\mathrm{H}$ activation step. ${ }^{12}$ As a consequence of attempting to change the adamantyl group in $\mathbf{2}$ with little success, we turned our attention to the carboxylate ligand and to the aryl group on the N-heterocyclic carbene (NHC). Thus, exchanging the pivalate group in $\mathbf{2}$ for other bi- $\left(\kappa^{2}\right)$ and monodentate $\left(\kappa^{1}\right)$ ligands, and the mesityl for various aryl groups, has resulted in several new derivatives that yield important insight into the reactivity and selectivity of this class of catalysts (Figure 1). Here, we report on the synthesis and selectivity of these new catalysts and demonstrate that several are capable of turnover numbers (TONs) approaching 1000 in cross-metathesis reactions while maintaining excellent $Z$-selectivity.

\section{RESULTS}

We initiated our studies by examining a range of ligands in place of the previously reported carboxylate (2). However, bulky carboxylates, such as pivalate, appear to be the only carboxylates capable of inducing the intramolecular C-H activation event necessary to form 2. As such, a new synthetic route was developed in order to access analogues of $\mathbf{2}$ possessing different X-type ligands. We found that reacting $\mathbf{2}$ with NaI in THF cleanly afforded the iodo-complex 3 that could then be used to prepare a wide range of catalysts via transmetallation with various silver salts (Scheme 1). Catalysts with monodentate $\mathrm{X}$-ligands were obtained in a similar manner. Notably, the nitrato-complex $\mathbf{7}$ could be formed by either reaction of $\mathbf{3}$ with $\mathrm{AgNO}_{3}$ or by direct reaction of $\mathbf{2}$ with $\mathrm{NH}_{4} \mathrm{NO}_{3}$, with the latter route being preferred (Scheme 2). Single crystal X-ray diffraction revealed that the nitrato ligand of $\mathbf{7}$ is coordinated in a bidentate fashion analogous to $\mathbf{2}$ (Figure 2). Structural parameters, including bond lengths and angles, were also consistent between $\mathbf{2}$ and $\mathbf{7}$.

The aryl substituent on the NHC (8-10) was varied through straightforward ligand synthesis, followed by metallation, and $\mathrm{C}-\mathrm{H}$ activation effected by silver pivalate (see the Supporting Information). In all cases, the pivalate was immediately exchanged for nitrate, since the nitrato complexes were generally more stable and easier to isolate. Only subtle steric and electronic modifications were introduced in the aryl group, as we found that the $\mathrm{C}-\mathrm{H}$ activation reaction is sensitive to more drastic changes, mainly resulting in decomposition. ${ }^{13}$

\section{Initiation Rates}

With a relatively diverse library of catalysts in hand, we began examining their reactivity in a range of olefin metathesis reactions. Reaction with butyl vinyl ether (BVE) was chosen as the first probe of catalyst activity since this reaction is commonly used to measure the initiation rate of ruthenium catalysts. ${ }^{14}$ As shown in Table 1, the initiation rate, measured by ${ }^{1} \mathrm{H}$ NMR spectroscopy, varied by two or more orders of magnitude for the examined catalysts! The most striking difference was observed between the catalysts containing bidentate $(\mathbf{2}, \mathbf{4 - 1 0})$ and monodentate $(\mathbf{3}, \mathbf{1 1})$ ligands. Whereas the bidentate complexes possessed initiation rates comparable to $\mathbf{1}$, complexes $\mathbf{3}$ and $\mathbf{1 1}$ initiated at significantly slower rates, even at higher temperatures. In particular, $\mathbf{1 1}$ showed almost no reactivity with BVE, even at temperatures as high as $70{ }^{\circ} \mathrm{C}$. From these data, we anticipated that the catalysts with monodentate ligands would be essentially metathesis inactive (vide infra).

Besides the differences between $\kappa^{1}$ and $\kappa^{2}$ ligands, several significant changes in initiation rate constant were observed between various bidentate ligands. For instance, exchanging pivalate (2) for the more electron donating 2,2-dimethoxypropanoate (6), led to a small increase in the rate constant. When the steric bulk of the carboxylate was increased (4) or decreased (5), initiation rate constants increased and decreased respectively. This last result 
was surprising since, in general, complexes with Hoveyda-type chelates are thought to initiate through an associative or associative-interchange mechanism. ${ }^{14 c, d}$ Thus, increasing the steric bulk of the carboxylate should have resulted in a decrease in the initiation rate constant due to the less favorable steric environment around the metal. The exact opposite was observed with the larger 2,2-dicyclohexylacetate (4) possessing a higher initiation rate than smaller carboxylate lignads $(\mathbf{2 , 5}$, and $\mathbf{6})$. Notably, electronic effects play an important role as evidenced by the differences between $\mathbf{6}$ and $\mathbf{2}$; thus, complexes of this type likely initiate through a different mechanism. Finally, the nitrato-complexes 7-9 had approximately the same initiation rate as $\mathbf{2}$, while that of $\mathbf{1 0}$ was slightly smaller. These results indicate that minor changes to the aryl group do not have a substantial effect on the rate of initiation of these catalysts.

\section{Cross-metathesis}

We next turned to evaluating these complexes in the homodimerization of allyl benzene (12). While this reaction is relatively facile for most metathesis catalysts, it provided a useful benchmark to assess the performance of our catalyst library (Table 2). Reactions were run in THF at $35^{\circ} \mathrm{C}$ with a relatively high substrate concentration (ca. $3 \mathrm{M}$ in 12) and 0.1 mol\% catalyst loading for a set amount of time, at which point the conversion and percentage of $Z$-olefin were measured by ${ }^{1} \mathrm{H}$ NMR spectroscopy. Low catalyst loadings were used to emphasize the differences between catalysts. In most cases, a detectable amount of olefin isomerization byproduct (14) was observed, but the amount of this undesired product and the total conversion of $\mathbf{1 2}$ varied significantly between catalysts. Catalysts 3 and 11 yielded the largest amount of 14; moreover, this was the only detectable product for these catalysts. Among the carboxylate-based catalysts, $\mathbf{4}$ was the least active, giving low conversion of $\mathbf{1 2}$ and poor selectivity for $\mathbf{1 3}$. Furthermore, no notable improvement was observed with complexes 5 and 6. Both $\mathbf{2}$ and 7-10 showed excellent conversion of 12 and good selectivity for 13, with catalysts 7-10 taking only $3 \mathrm{~h}$ to reach $\sim 90 \%$ conv. In addition, these catalysts were able to maintain very high $Z$-selectivity, even at high levels of conversion. Catalysts 7-10 afford similar conversions of $\mathbf{1 2}$ compared to $\mathbf{2}$, and are clearly the most efficient of the catalysts examined as they are able to achieve high conversion with good selectivity for the $Z$-isomer of $\mathbf{1 3}$ while forming only a marginal amount of the undesired product 14 .

In order to further differentiate the performance of the catalysts, the more challenging substrate methyl 10-undecenoate (15) was examined in the homodimerization reaction (Table 3, 12Figure 3). For this reaction, only the catalysts that performed well in the reaction with were examined, namely the carboxylate and nitrato catalysts. Similar to the homodimerization of 12, low loadings were used to differentiate the catalysts. We were pleased to discover that even at $0.1 \mathrm{~mol} \%$ loading, most of the catalysts were able to achieve an appreciable degree of conversion. The exception was catalyst $\mathbf{4}$, which showed no conversion until the catalyst loading was increased to $2 \mathrm{~mol} \%$. Similar to the reaction with 12, catalysts 4-6 performed relatively poorly while 2 and 7-10 furnished the best results. In fact, catalysts 7-10 showed excellent conversion (>90\%) at short reaction times and low catalyst loading ( $0.1 \mathrm{~mol} \%)$ with good selectivity for the Z-olefin (90-95\%, Figure 3 ). This is a clear demonstration of their superior activity and selectivity. A time-course monitoring of the reaction of $\mathbf{1 5}$ with catalysts 7-10 revealed some subtle differences between the nitrato catalysts (Figure 3). Specifically, there were only slight variations in both conversion and Z-selectivity for catalysts 7-9 which is consistent with the initiation rate constants measured for these catalysts and their reactivity with $\mathbf{1 2}$. At shorter reaction times, $\mathbf{1 0}$ showed slightly reduced reaction conversion compared to its analogues, which is likely a consequence of its slower initiation rate. Nonetheless, given enough time, $\mathbf{1 0}$ was able to reach similar levels of conversion as 7-9. Finally, the time-course study demonstrates that, 
at least for this substrate, secondary metathesis events are relatively slow, as $Z$-selectivity remains high even after extended periods of time at ca. $90 \%$ conversion. ${ }^{15}$

The two aforementioned metathesis assays clearly demonstrated the superior activity of the nitrato catalysts 7-10 over the carboxylate analogues. However, it was still unclear if this effect was specific to the chosen substrates. To fully evaluate the effectiveness of 7-10, several other substrates, including alcohols, were examined (Table 4). For the majority of these reactions, catalysts 7-10 were easily capable of reaching TON greater than 500 and, in some cases, coming close to 1000. Notably, the yields presented in Table 4 are calculated based on isolated yield, meaning that the actual TONs are likely to be higher. Certain substrates, such as $\mathbf{1 9}$ and 20, were less reactive and resulted in reduced TONs. At this time, we believe this attenuation is not a result of the functional group itself, but of its proximity to the reacting olefin. Nevertheless, the TONs for these substrates are still respectable. The nitrato-complexes 7-10 showed almost no significant differences in either conversion or Zselectivity for the substrates where they were directly compared. ${ }^{15}$ Finally, the selectivity for the Z-olefin was excellent in almost every case, demonstrating the superiority of these catalysts.

Having established the effectiveness of $\mathbf{7}$ in several homodimerization reactions, we turned our attention to more complex reactions including the "standard" cross-metathesis reaction between 12 and cis-1,4-diacetoxybutene (24). ${ }^{16}$ Similar to the case of olefin homodimerization, lowering the temperature and increasing the substrate concentration resulted in higher conversion to the desired product (25) with comparable selectivity for the Z-olefin (Table 5). For this assay, all of the carboxylate catalysts performed roughly the same, reaching around 15 TONs; however, significant amounts of 13 were also formed in each reaction. In contrast, 7 was able to achieve similar levels of conversion at catalyst loadings as low as $1 \mathrm{~mol} \%$. Furthermore, since $\mathbf{2 4}$ possibly interferes with 7, as shown by the low TONs achieved in the homodimerization of $\mathbf{1 9}$, we suspected that a judicious choice of substrates would allow for the catalyst loading to be lowered even further.

Subsequently, we selected $\mathbf{2 8}$ (Scheme 3) as a synthetic target because of its industrial relevance in insect pest control, and the fact that the functionality is far removed from the olefin. Insect pheromones similar to $\mathbf{2 8}$ have been prepared via olefin metathesis before, but those containing $Z$-olefins have largely eluded this methodology. ${ }^{17}$ Thus, the preparation of 28 represented an opportunity to demonstrate the high activity and selectivity of $\mathbf{7}$ in an industrially relevant reaction. Gratifyingly, reaction of $\mathbf{2 6}$ with $\mathbf{2 7}$ to form $\mathbf{2 8}$ proceeded in high yield (77\%) with catalyst loadings as low as $0.5 \mathrm{~mol} \%$ and with excellent selectivity (>90\%) for the Z-product (Scheme 3) ${ }^{18}$ More importantly, the use of $\mathbf{7}$ in this reaction allows for the preparation of $\mathbf{2 8}$ in 1 step, as opposed to the previously reported 6 step synthesis. ${ }^{19}$ Thus, catalysts such as $\mathbf{7}$ should allow for the efficient synthesis of $Z$-olefin containing pheromones and other natural products via metathesis with minimal catalyst loadings.

\section{DICUSSION}

As mentioned above, we have previously established that the adamantyl group in catalysts 2-11 is critical for achieving high levels of $Z$-selectivity. ${ }^{9 a}$ The results presented here clearly demonstrate that the other $\mathrm{X}$-type ligand plays an important role in reactivity, stability, and selectivity as well. The best demonstration of the significance of this ligand is the observed difference in initiation rates, where catalysts containing monodentate ligands ( $\mathbf{3}$ and $\mathbf{1 1}$ ) were essentially unreactive. This result implies that bidentate ligands are unique in their ability to induce catalyst initiation. Although ruthenium catalysts containing carboxylate ${ }^{20}$ or nitrato ${ }^{21}$ ligands are well-known, to the best of our knowledge, there has been no report 
on their initiation behavior, at least for Hoveyda-type systems. However, analogues of $\mathbf{1}$ containing carboxylate or other bidentate ligands are generally metathesis active, ${ }^{22}$ which is an indication that special ligands are not required for standard catalysts to initiate. It is also worth noting that the replacement of chlorides or carboxylates with nitrate in other ruthenium complexes generally resulted in less active and less selective metathesis catalysts. Thus, the C-H activated catalysts, which show the opposite trend, appear to be unique in this regard.

A more general understanding of catalyst initiation can be gained by considering the differences in rates between complexes within the same family (e.g. carboxylates). For instance, electron-donating and bulky groups resulted in an increase in initiation rate while smaller groups lead to a decrease in rate. Considering these results, it would have been interesting to probe the effect of electron-withdrawing carboxylates (e.g. trifluoroacetate); however, we found that such complexes were unstable and immediately decomposed upon anion exchange. ${ }^{23}$ Overall, the differences in initiation rates between catalysts with different carboxylates imply that a simple associative or associative-interchange mechanism is not occurring and that catalysts such as $\mathbf{2}$ likely undergo multiple pre-equilibrium steps (e.g. an equilibrium between $\kappa^{2}$ and $\kappa^{1}$ coordination, and an equilibrium between association and dissociation of the chelated oxygen) prior to reaction with olefin.

Unfortunately, while our initiation rate studies allowed us to identify poor or unreactive catalysts (e.g. with monodentate ligands), they have not correlated well with actual metathesis reactivity. Consider, for instance, the negligible difference in initiation rate between $\mathbf{1}$ and $\mathbf{4}$. From this result, we predicted that these two complexes might have similar reactivity. A time-course plot for the conversion of cyclooctadiene (COD) during ringopening metathesis polymerization (ROMP) revealed that this is clearly not the case (Figure S4). Catalyst $\mathbf{1}$ is able to complete this reaction within minutes, while $\mathbf{4}$ only reacts over a period of hours and never reaches full conversion. Furthermore, when compared with $\mathbf{2}$ and 7, 4 is clearly inferior in both activity and selectivity despite its greater initiation rate.

Therefore, simply increasing the initiation rate of this class of catalysts will not necessarily result in increased activity. On the other hand, decreasing the initiation rate does not result in an improved catalyst either. In the extreme case, this was shown by the inactivity of monodentate ligands, but it was also demonstrated by the lower activity of $\mathbf{5}$. These observations parallel the behavior of previous generations of ruthenium metathesis catalysts. ${ }^{14 a}$ Although a complete mechanistic understanding of initiation for $\mathrm{C}-\mathrm{H}$ activated catalysts remains unclear, the observed discrepancies between initiation rates and actual metathesis activity can most likely be explained by the fact that the method used to measure initiation does not take into account either the reversibility of metathesis reactions or degenerate metathesis events. ${ }^{24}$ Both of these factors likely have a significant effect on the reactivity of $\mathrm{C}-\mathrm{H}$ activated catalysts, particularly in cross-metathesis reactions.

In contrast to the various carboxylate ligands, changes to the aryl group on the NHC had little to no effect on catalyst initiation and activity. One exception was the replacement of mesityl (7) with 2,6-dimethyl-4-chlorobenzene (10), which results in a marginal attenuation of initiation rate. Nonetheless, this only slightly affects catalytic activity as evidenced by the small differences in turnover frequency (TOF) between $\mathbf{7}$ and 10. As mentioned earlier, we have been unable to access aryl groups significantly different from mesityl due to decomposition upon attempted C-H activation. For instance, we have demonstrated that ortho substitution of the aryl ring is required to prevent undesired $\mathrm{C}-\mathrm{H}$ activation and subsequent decomposition. ${ }^{12}$ The remote nature of this part of the NHC ligand makes the predictability of structural effects on catalyst activity and selectivity difficult. ${ }^{25}$ Additionally, the unpredictability associated with the synthesis of C-H activated catalysts 
with different $N$-aryl groups renders such modifications less convenient for catalyst optimization.

In actual cross-metathesis reactions, the nitrato catalysts $\mathbf{7 - 1 0}$ were the best catalysts in terms of both activity and selectivity. At this time, we believe this is a result of the nitrato ligand imparting greater stability to the complex compared with carboxylates. Qualitatively, 7-10 were far more tolerant to oxygen than the carboxylate analogues and also easier to purify. ${ }^{26}$ The reasons for this enhanced stability are unclear at this time, but there are clearly substantial steric and electronic effects at play. The enhanced stability of the nitrato catalysts also influences the balance between conversion and $Z$-selectivity over the course of the reaction.

As with Mo- and W-based catalysts, the relationship between conversion and Z-selectivity is critical and warrants further discussion. ${ }^{8 c}$ At low reaction conversions, $\mathbf{7}$ is almost perfectly selective for the $Z$-olefin. Unfortunately, as conversion increases, $Z$-selectivity decreases at a rate dependent on the nature of the substrate and the catalyst, although it typically stays above $70 \% .^{15}$ An illustration of this phenomenon was presented in Table 4, specifically, the homodimerization of $\mathbf{1 8}$ with $\mathbf{2}$ and $\mathbf{7}$. The observed decrease in selectivity may be due to secondary metathesis events or hydride-induced olefin isomerization. ${ }^{27}$ A secondary metathesis mechanism would require the generation of a nonselective metathesis active decomposition product, since the initial catalyst is very selective. Several possible structures can be envisioned, the most likely of which would be a catalyst resulting from cleavage of the Ru-C (adamantyl) bond. Thus far, we have been unable to detect or isolate any species which may be responsible for secondary metathesis. On the other hand, the existence of ruthenium hydrides can be inferred by the observation of olefin migration in the reaction of 12. Moreover, these species can also be detected by ${ }^{1} \mathrm{H}$ NMR spectroscopy under specific conditions. ${ }^{28}$ We have attempted to suppress the generation of hydride species with various chemical quenchers, but have been unable to achieve this thus far. ${ }^{29}$ Consequently, the design of new catalysts that are less susceptible to either secondary metathesis or hydride formation is of paramount importance. For now, individual researchers must prioritize either conversion or $Z$-selectivity with substrates that are more susceptible to isomerization.

In summary, we have prepared a variety of new C-H activated ruthenium catalysts for Zselective olefin metathesis. Adjusting the ligand environment around the metal center has yielded significant insight into the initiation behavior, activity, and selectivity of this class of catalysts and has facilitated the development of improved catalysts (7-10) that are capable of ca. 1000 TONs in several cross-metathesis reactions. We note that these catalysts can be used with very low loadings, and do not require reduced pressures, high temperatures, or rigorous exclusion of protic solvents in order to operate effectively. Secondary metathesis events are also relatively slow for the majority of substrates, meaning that significant reaction optimization should not be required. Based on these attributes, we anticipate that catalysts such as $\mathbf{7}$ will be swiftly adopted by both industrial and academic researchers interested in the construction of $Z$-olefins using metathesis methodology.

\section{Supplementary Material}

Refer to Web version on PubMed Central for supplementary material.

\section{Acknowledgments}

Lawrence Henling and Dr. Michael Day are acknowledged for X-ray crystallographic analysis. Dr. David VanderVelde is thanked for assistance with NMR experimentation and analysis. This work was financially supported by the NIH (NIH 5R01GM031332-27), the NSF (CHE-1048404), Mitsui Chemicals, Inc. (K.E.), and the NDSEG (fellowship to B.K.K.). Instrumentation facilities on which this work was carried out were supported by 
the NSF (X-ray diffractometer, CHE-0639094) and the NIH (NMR spectrometer, RR027690). Materia, Inc. is thanked for its donation of metathesis catalysts.

\section{References}

1. (a) Fürstner A. Angew Chem Int Ed. 2000; 39:3012.(b) Trnka TM, Grubbs RH. Acc Chem Res. 2001; 34:18. [PubMed: 11170353] (c) Astruc D. New J Chem. 2005; 29:42.

2. (a) Schrock RR, Hoveyda AH. Angew Chem Int Ed. 2003; 42:4592.(b) Samojowicz C, Bieniek M, Grela K. Chem Rev. 2009; 109:3708. [PubMed: 19534492] (c) Vougioukalakis GC, Grubbs RH. Chem Rev. 2010; 110:1746. [PubMed: 20000700]

3. (a) Leitgeb A, Wappel J, Slugovc C. Polymer. 2010; 51:2927.(b) Sutthasupa S, Shiotsuki M, Sanda F. Polymer Journal. 2010; 42:905.(c) Liu X, Basu A. J Organomet Chem. 2006; 691:5148.

4. Cossy, J.; Arseniyadis, S.; Meyer, C. Metathesis in Natural Product Synthesis: Strategies, Substrates, and Catalysts. 1. Wiley-VCH; Weinheim, Germany: 2010.

5. Binder JB, Raines RT. Curr Opin Chem Bio. 2008; 12:767. [PubMed: 18935975]

6. Schrodi Y, Ung T, Vargas A, Mkrtumyan G, Lee CW, Champagne TM, Pederson RL, Hong SH. CLEAN - Soil, Air, Water. 2008; 36:669.

7. (a) Wang Y, Jimenez M, Hansen AS, Raiber EA, Schreiber SL, Young DW. J Am Chem Soc. 2011; 133:9196. [PubMed: 21557625] (b) Gallenkamp D, Fürstner A. J Am Chem Soc. 2011; 133:9232. [PubMed: 21604689]

8. (a) Jiang AJ, Zhao Y, Schrock RR, Hoveyda AH. J Am Chem Soc. 2009; 131:16630. [PubMed: 19919135] (b) Marinescu SC, Schrock RR, Muller P, Takase MK, Hoveyda AH. Organometallics. 2011; 30:1780. [PubMed: 21686089] (c) Meek SJ, O’Brien RV, Llaveria J, Schrock RR, Hoveyda AH. Nature. 2011; 471:461. [PubMed: 21430774] (d) Marinescu SC, Levine DS, Zhao Y, Schrock RR, Hoveyda AH. J Am Chem Soc. 2011; 133:11512. [PubMed: 21718001]

9. (a) Endo K, Grubbs RH. J Am Chem Soc. 2011; 133:8525. [PubMed: 21563826] (b) Keitz BK, Endo K, Herbert MB, Grubbs RH. J Am Chem Soc. 2011; 133:9686. [PubMed: 21649443]

10. (a) Trnka TM, Morgan JP, Sanford MS, Wilhelm TE, Scholl M, Choi TL, Ding S, Day MW, Grubbs RH. J Am Chem Soc. 2003; 125:2546. [PubMed: 12603143] (b) Leitao EM, Dubberley SR, Piers WE, Wu Q, McDonald R. Chem Eur J. 2008; 14:11565. [PubMed: 19035588] (c) Galan BR, Pitak M, Gembicky M, Keister JB, Diver ST. J Am Chem Soc. 2009; 131:6822. [PubMed: 19397262]

11. (a) Romero PE, Piers WE, McDonald R. Angew Chem Int Ed. 2004; 43:6161.(b) Wenzel AG, Grubbs RH. J Am Chem Soc. 2006; 128:16048. [PubMed: 17165753] (c) Romero PE, Piers WE. J Am Chem Soc. 2007; 129:1698. [PubMed: 17243686] (d) Rowley CN, Eide E, van der F, Piers WE, Woo TK. Organometallics. 2008; 27:6043.(e) Eide E, van der F, Romero PE, Piers WE. J Am Chem Soc. 2008; 130:4485. [PubMed: 18321104] (f) Leitao EM, Eide E, van der F, Romero PE, Piers WE, McDonald R. J Am Chem Soc. 2010; 132:2784. [PubMed: 20136131] (g) Eide E, van der F, Piers WE. Nature Chemistry. 2010; 2:571.(h) Keitz BK, Grubbs RH. J Am Chem Soc. 2011; 133:16277. [PubMed: 21919449]

12. A more thorough analysis of decomposition structures related to 2 will be reported in a subsequent communication.

13. For instance, both $\mathrm{Ar}=2,6$-di- $i$-propylphenyl and 3,5-t-butylphenyl formed unstable complexes upon exposure of the precursors to silver pivalate.

14. (a) Sanford MS, Love JA, Grubbs RH. J Am Chem Soc. 2001; 123:6543. [PubMed: 11439041] (b) Hejl, A. PhD Dissertation. California Institute of Technology; 2007. (c) Vorfalt T, Wannowius KJ, Plenio H. Agnew Chem Int Ed. 2010; 1:5533.(d) Ashworth IW, Hillier IH, Nelson DJ, Percy JM, Vincent MA. Chem Comm. 2011; 47:5428. [PubMed: 21483970]

15. Time-course plots for substrates $\mathbf{1 2}$ and $\mathbf{1 8}$ can be found in the Supporting Information.

16. Ritter T, Hejl A, Wenzel AG, Funk TW, Grubbs RH. Organometallics. 2006; 25:5740.

17. (a) Banasiak DS. J Mol Catal. 1985; 28:107.(b) Pederson RL, Fellows IM, Ung TA, Ishihara H, Hajela SP. Adv Synth Catal. 2002; 344:728.(c) Mol J. J Mol Catal A Chem. 2004; 213:39.(d) Mori K. Tetrahedron. 2009; 65:2798.(e) Mori K. Tetrahedron. 2009; 65:3900.(f) Mori K, Tashiro T, Zhao B, Suckling DM, El-Sayed AM. Tetrahedron. 2010; 66:2642. 
18. The stereochemistry of 28 was confirmed by ${ }^{1} \mathrm{H}$ and ${ }^{13} \mathrm{C}$ NMR spectroscopy in conjunction with 2D techniques including COSY and HSQC. Further confirmation was obtained using IR spectroscopy. See the Supporting Information for details.

19. Subbaraman AS, Mithran S, Mamdapur VR. Molecules. 1998; 3:35.

20. Krause JO, Nuyken O, Wurst K, Buchmeiser MR. Chem Eur J. 2004; 10:777. [PubMed: 14767943]

21. (a) Jovic M, Torker S, Chen P. Organometallics. 2011; 30:3971.(b) Buchmeiser MR, Ahmad I, Gurram V, Kumar PS. Macromolecules. 2011; 44:4098.

22. (a) Buchowicz W, Mol JC, Lutz M, Spek AL. J Organomet Chem. 1999; 588:205.(b) Buchowicz W, Ingold F, Mol JC, Lutz M, Spek AL. Chem Eur J. 2001; 7:2842. [PubMed: 11486961] (c) Krause JO, Nuyken O, Wurst K, Buchmeiser MR. Chem Eur J. 2004; 10:777. [PubMed: 14767943] (d) Kumar PS, Wurst K, Buchmeiser MR. J Am Chem Soc. 2009; 131:387. [PubMed: 19128182]

23. Addition of Silver (I) Trifluoroacetate to $\mathbf{3}$ resulted in an immediate color change from brown to yellow. X-ray characterization of the isolated product revealed a structure that contained an $\eta^{2}$ olefin resulting from insertion into the carbene followed by $\beta$-hydride elimination.

24. Stewart IC, Keitz BK, Kuhn KM, Thomas RM, Grubbs RH. J Am Chem Soc. 2010; 132:8534. [PubMed: 20518557]

25. For a discussion of the effect of the NHC aryl group on ruthenium metathesis catalysts see: (a) Süssner M, Plenio H. Chem Comm. 2005:5417. [PubMed: 16261232] (b) Stewart IC, Benitez D, O’Leary DJ, Tkatchouk E, Day MW, Goddard WA, Grubbs RH. J Am Chem Soc. 2009; 131:1931. [PubMed: 19146414] (c) Ragone F, Poater A, Cavallo L, Chimica D. J Am Chem Soc. 2010; 132:4249. [PubMed: 20205432]

26. For instance, when a solution of 7 in $\mathrm{C}_{6} \mathrm{D}_{6}$ was exposed to air, the benzylidene resonance of 7 was still observed by ${ }^{1} \mathrm{H}$ NMR spectroscopy after $12 \mathrm{~h}$. In contrast, the benzylidene resonance of 2 disappeared after only $2 \mathrm{~h}$ following exposure to air.

27. For selected examples of olefin migration/isomerization catalyzed by ruthenium hydrides see: (a) Bourgeois D, Pancrazi A, Nolan SP, Prunet J. J Organomet Chem. 2002; 643/644:247.(b) Sworen JC, Pawlow JH, Case W, Lever J, Wagener KB. J Mol Catal A: Chem. 2003; 194:69.(c) Krompiec S, KuŸnik N, Penczek R, Rzepa J, Mrowiec-Białon J. J Mol Catal A: Chem. 2004; 219:29.(d) Krompiec S, KuŸnik N, Krompiec M, Penczek R, Mrzigod J, Tórz A. J Mol Catal A: Chem. 2006; 253:132.(e) Faller JW, Fontaine PP. Organometallics. 2007; 26:1738.(f) Alcaide B, Almendros P, Luna A. Chem Rev. 2009; 109:3817. [PubMed: 19572654]

28. C-H activated catalysts with certain carboxylates will, upon mild heating, cleanly decompose into ruthenium hydride species. Unfortunately, we have been unable to structurally characterize these species: Keitz BK, Grubbs RH. Unpublished Results.

29. Some additives, like 1,4-benzoquinone, led to immediate catalyst decomposition, while milder compounds, such as $\alpha, \alpha$-dichlorotoluene, resulted in decreased reaction conversions. 

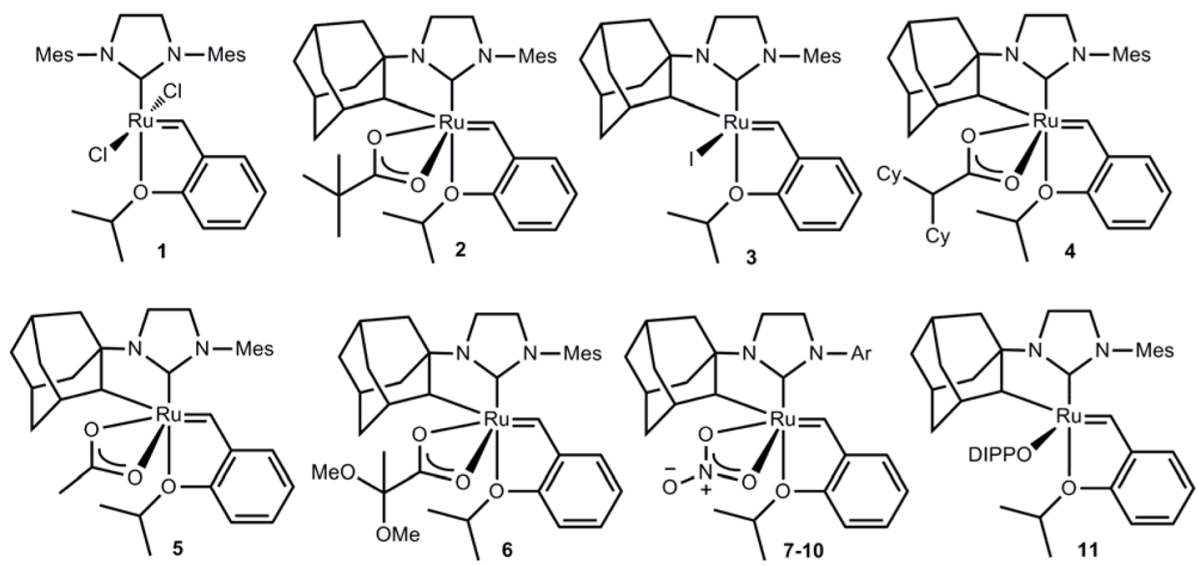

Figure 1.

Catalysts 1-11. Ar = 2,4,6-trimethylbenzene (7), 2,6-diethyl-4-methylbenzene (8), 2,6dimethyl-4-methoxybenzene (9), 2,6-dimethyl-4-chlorobenzene (10). Mes = 2,4,6trimethylbenzene. DIPP = 2,6-di-i-propylbenzene. 


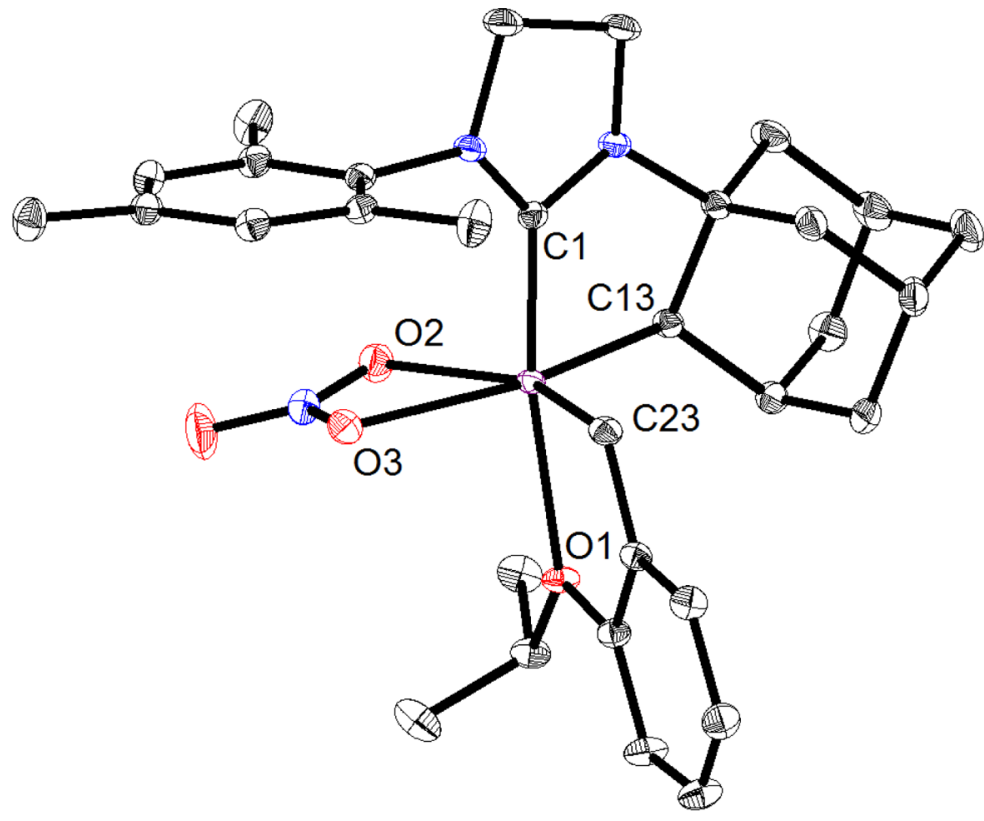

Figure 2.

Solid-state structure of 7 with thermal ellipsoids drawn at $50 \%$ probability. Selected bond lengths $(\AA)$ for 7. C1-Ru: 1.961, C13-Ru: 2.057, C23-Ru: 1.838, O1-Ru: 2.320, O2-Ru: 2.367, O3-Ru: 2.209 . 

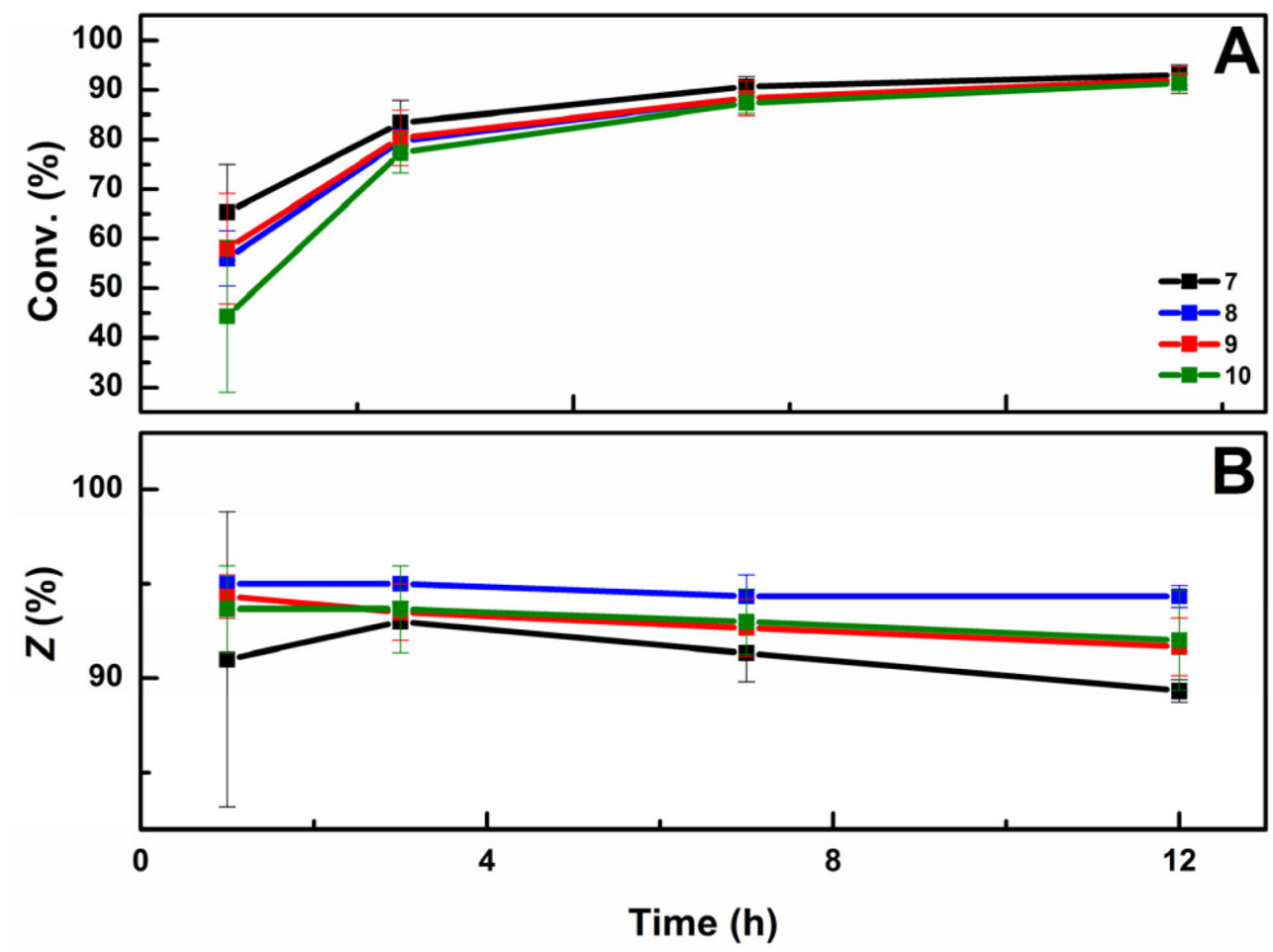

Figure 3.

Time-course plot for the conversion (A) and selectivity (B) of homodimerization of $\mathbf{1 5}$ to $\mathbf{1 6}$ using catalysts 7-10. Conditions were $\mathbf{1 5}(1 \mathrm{mmol})$, catalyst $(1 \mu \mathrm{mol})$, in THF $(0.1 \mathrm{~mL})$ at 35 ${ }^{\circ} \mathrm{C}$. Data points and error bars were calculated from the average and standard deviation of three separate runs. 


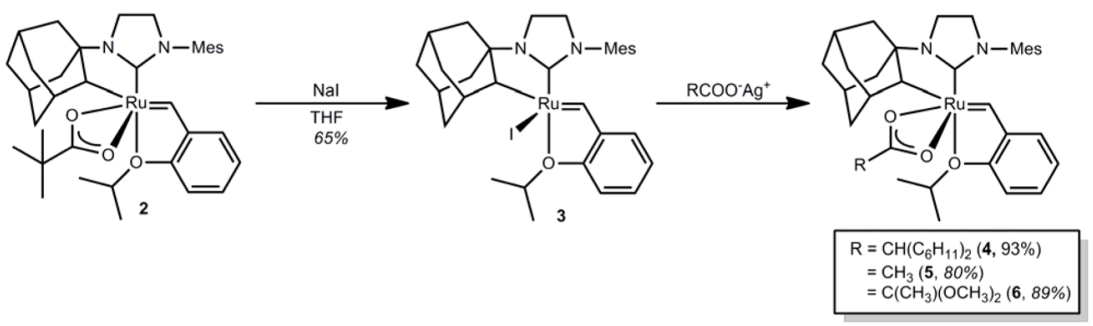

Scheme 1.

Preparation of catalysts 3-6. 

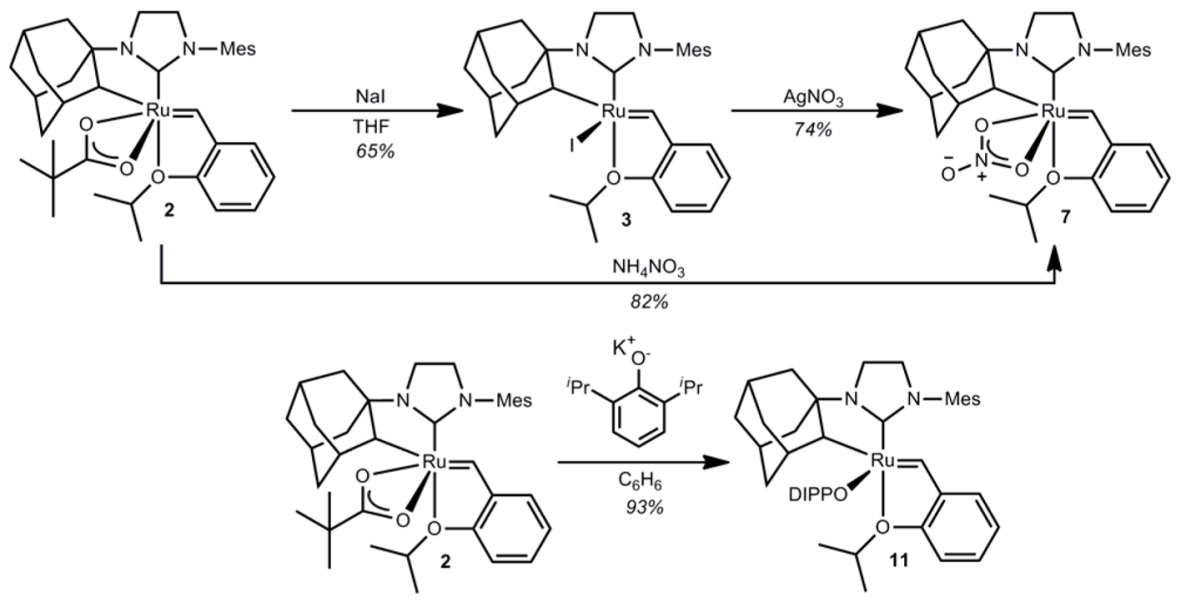

Scheme 2.

Preparation of catalysts $\mathbf{7}$ and $\mathbf{1 1}$. 


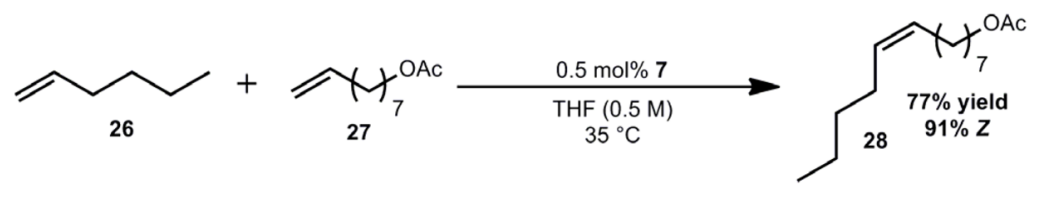

Scheme 3.

Synthesis of $\mathbf{2 8}$ using catalyst $\mathbf{7}$. 
Table 1

Initiation rates for catalysts $\mathbf{1 - 1 1 .}{ }^{a}$

\begin{tabular}{ccc}
\hline Catalyst & Temp, $^{\circ} \mathbf{C}$ & Initiation Rate Constants, $\mathbf{1 0}^{\mathbf{- 3}} \mathbf{s}^{\mathbf{- 1}}$ \\
\hline $\mathbf{1}$ & 30 & $7.2 \pm 0.2$ \\
$\mathbf{2}$ & 30 & $0.87 \pm 0.02$ \\
$\mathbf{3}$ & 50 & $0.17 \pm 0.01$ \\
$\mathbf{4}$ & 30 & $6.9 \pm 0.3$ \\
$\mathbf{5}$ & 30 & $0.17 \pm 0.04$ \\
$\mathbf{6}$ & 30 & $2.5 \pm 0.1$ \\
$\mathbf{7}$ & 30 & $0.84 \pm 0.03$ \\
$\mathbf{8}$ & 30 & $0.77 \pm 0.05$ \\
$\mathbf{9}$ & 30 & $0.76 \pm 0.02$ \\
$\mathbf{1 0}$ & 30 & $0.24 \pm 0.05$ \\
$\mathbf{1 1}$ & 70 & $<0.39^{b}$
\end{tabular}

${ }^{a}$ Initiation rate constants were determined by measuring the decrease in the benzylidene resonance using ${ }^{1} \mathrm{H}$ NMR spectroscopy following addition of BVE. Conditions were catalyst $(0.003 \mathrm{mmol}), \mathrm{BVE}(0.09 \mathrm{mmol})$, in $\mathrm{C}_{6} \mathrm{D}_{6}(0.6 \mathrm{~mL})$ at given temperature.

${ }^{b}$ Value based on single half-life of $\mathbf{1 1}$. 
Table 4

Homodimerization of terminal olefin substrates. ${ }^{a}$

\begin{tabular}{|c|c|c|c|c|}
\hline \multicolumn{3}{|c|}{$0.1 \mathrm{~mol} \%$ catalyst } & & \multirow[b]{3}{*}{ Yield, $c \%$} \\
\hline \multirow[b]{2}{*}{ Substrate } & \multicolumn{2}{|c|}{$\begin{array}{c}\operatorname{THF}(3 \mathrm{M}) \\
35^{\circ} \mathrm{C}\end{array}$} & \multirow[b]{2}{*}{$\mathrm{z}, \boldsymbol{b} \%$} & \\
\hline & Catalyst & Time, $\mathbf{h}$ & & \\
\hline \multirow{5}{*}{ Allyl benzene (12) } & 2 & 3 & 86 & 73 \\
\hline & 7 & 3 & 92 & 91 \\
\hline & 8 & 3 & 94 & 91 \\
\hline & 9 & 3 & 95 & 83 \\
\hline & 10 & 3 & 95 & 89 \\
\hline \multirow{5}{*}{ Methyl 10-undenenoate (15) } & 2 & 12 & 90 & 13 \\
\hline & 7 & 12 & 91 & 85 \\
\hline & 8 & 12 & 92 & 94 \\
\hline & 9 & 12 & 92 & 92 \\
\hline & 10 & 12 & 94 & 75 \\
\hline \multirow{2}{*}{ 1-octene (17) } & 2 & 12 & 94 & 30 \\
\hline & 7 & 12 & 92 & 83 \\
\hline \multirow{5}{*}{ 4-penten-1-ol (18) } & 2 & 12 & 43 & 81 \\
\hline & 7 & 12 & 81 & 67 \\
\hline & 8 & 8 & 73 & 78 \\
\hline & 9 & 8 & 78 & 76 \\
\hline & 10 & 8 & 85 & 75 \\
\hline Allyl acetate (19) & 7 & 12 & $>95$ & $-d$ \\
\hline $\mathrm{N}$-allylaniline (20) & 7 & 12 & 90 & 12 \\
\hline 2-(allyloxy)ethanol (21) & 7 & 12 & 67 & 30 \\
\hline Allyl pinacol borane (22) & 7 & 3 & $>95$ & 36 \\
\hline Allyl TMS (23) & 7 & 9 & $>95$ & 14 \\
\hline
\end{tabular}

${ }^{a}$ Conditions were catalyst $(5 \mu \mathrm{mol})$ and substrate $(5 \mathrm{mmol})$ in $\mathrm{THF}(\mathrm{ca} .1 .7 \mathrm{~mL})$ at $35^{\circ} \mathrm{C}$.

${ }^{b}$ Determined by ${ }^{1}$ H NMR spectroscopy.

${ }^{c}$ Isolated yield after chromatography.

$d_{\text {Yield not determined. }}$ 


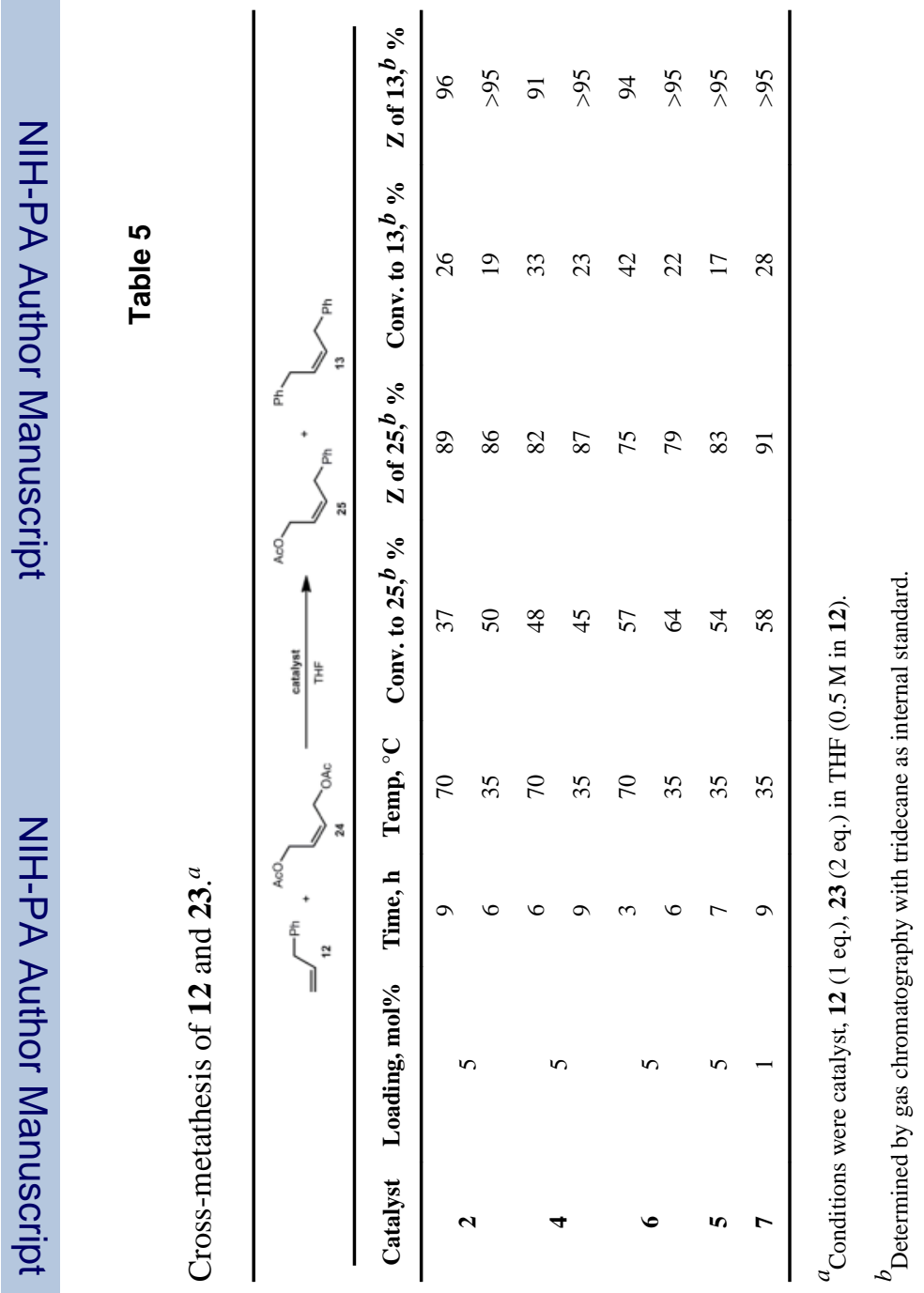

J Am Chem Soc. Author manuscript; available in PMC 2013 January 11. 